\title{
Implicações da gestão ambiental em microempresa de manutenção automotiva em Lajeado, Rio Grande do Sul, Brasil
}

\section{Nara Paula Schmeier ${ }^{1}$ e Wemerson de Castro Oliveira ${ }^{2}$}

${ }^{1}$ Instituto Federal de Educação, Ciência e Tecnologia Sul-Rio-Grandense. Curso de Especialização em Gestão de Micro e Pequenos Negócios. Campus Lajeado. Rua João Goulart, 2150. Olarias. Lajeado-RS, Brasil (CEP 95910-016).

${ }^{2}$ Instituto Federal de Educação, Ciência e Tecnologia Sul-Rio-Grandense. Departamento de Ensino, Pesquisa e Extensão. Campus Lajeado. Rua João Goulart, 2150. Olarias. Lajeado-RS, Brasil (CEP 95910-016). E-mail: wemersonoliveira@ifsul.edu.br.

Resumo. Diante da questão de como a implantação de práticas de gestão e educação ambiental em oficina de reparação automotiva pesada poderiam influenciar a sistemática de trabalho da empresa, objetivou-se com está pesquisa analisar a gestão de resíduos sólidos gerados nas atividades de uma oficina mecânica e identificar como práticas de gestão ambiental podem contribuir para a melhora do desempenho organizacional em termos de processos e serviços. A metodologia foi balizada por uma abordagem exploratória e descritiva mediante coleta de dados em duas etapas, (a) aplicação de um questionário estruturado com 12 perguntas, objetivas e discursivas, com todos os colaboradores e gestores da empresa, e (b) visitas técnicas para registro e tabulação das não conformidades baseadas em normativas ambientais. Com o estudo identificou-se conformidades e não conformidades na gestão ambiental da empresa e a partir disso, propostas de melhorias foram apresentadas para atendimento à legislação ambiental. Percebeu-se também que a equipe da empresa, gestores e colaboradores, apresenta compreensão e entendimento satisfatório frente às questões ambientais inerentes às atividades que desempenham. Por fim, conclui-se que as práticas de gestão ambiental adotadas pela empresa contribuíram na melhoria do seu desempenho organizacional interno, apesar destas práticas não serem percebidos por seus clientes.

Palavras-chave: Educação ambiental; Gestão de resíduos; Oficina mecânica; Desempenho organizacional; Marketing ambiental.

Abstract. Implications of environmental management in an automotive maintenance microenterprise in Lajeado, Rio Grande do Sul, Brazil. Faced with the question of how the implementation of management practices and environmental education in a heavy automotive repair shop boosted the
Recebido

$28 / 06 / 2021$

Aceito

$26 / 07 / 2021$

Disponível on line

$31 / 07 / 2021$

Publicado

$31 / 08 / 2021$

Acesso aberto

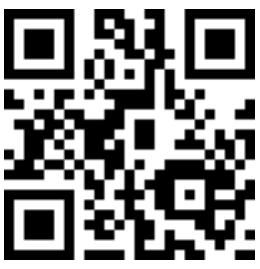

ORCID

(1) 0000-0002-2124-806X Nara Paula Schmeier

(D) 0000-0001-7256-265X Wemerson de Castro Oliveira 
company's work system, the objective was to research the management of solid waste generated in the activities of a machine shop and identify how practices Environmental management can contribute to improving organizational performance in terms of processes and services. The methodology was guided by an exploratory and descriptive approach through data collection in two stages: (a) application of a structured questionnaire with 12 questions, objective and discursive, with all employees and managers of the company; and (b) technical visits to record and tabulate non-compliances based on environmental standards. With the study, the conformity and non-conformities in the company's environmental management were identified and, based on that, proposals for improvements were necessary to comply with environmental legislation. It was also noticed that the company's team, managers and employees, understand and satisfactorily understand the environmental issues inherent to the activities they perform. Finally, it is concluded that the environmental management practices adopted by the company contributed to the improvement of its internal organizational performance, despite these practices not being perceived by its customers.

Keywords: Environmental education; Waste Management; Mechanical workshop; Organizational performance; Environmental marketing.

\section{Introdução}

No cenário econômico atual, é observado um crescimento numérico e opcional de estabelecimentos voltados a prestação de serviços visando a atender as mais diversas demandas da população. Neste contexto, os serviços de reparação automotiva compõem o cenário de forma significativa, uma vez que o número de veículos nas ruas tem aumentado substancialmente, desencadeando um aumento na demanda por serviços especializados de manutenção. Em paralelo, este tipo de serviço gera resíduos que podem causar impactos ambientais significativos, acarretando na necessidade de regularização e adequação ambiental da atividade (Belfi et al., 2014). A questão ambiental, apesar de sempre ter existido, conquistou a atenção mundial com maior expressividade ao final do último século. Fatores como o aumento da temperatura global, efeito estufa, aumento e destinação dos resíduos gerados e mudanças climáticas estão em evidência e dão sinais de alerta de que toda a atividade humana produz resíduos, tornando obrigatória a adoção de medidas paliativas para reduzir o impacto ambiental e o comprometimento do planeta (Silveira et al., 2010).

De acordo com Oliveira et al. (2008) o monitoramento ambiental pode contribuir significativamente nas tomadas de decisão, por meio da compreensão do ambiente no qual as empresas realizam suas atividades. Os autores também trazem que mapear o ambiente propicia a organização e compreensão das forças externas, além de fornecer informações necessárias para que ela responda assertivamente às mudanças e assegure a sua permanência no mercado no qual atua. Em se tratando do processo, são indicados cinco passos básicos para o monitoramento ambiental na empresa: (a) buscar informações; (b) selecionar os recursos de informações que sejam monitoráveis, (c) definir os critérios de monitoramento; (d) atividade de monitoria propriamente dita; e (e) determinar as ações 
preventivas ou corretivas a serem tomadas (Oliveira et al., 2008). Além disso, as empresas que pretendem adotar uma postura mais preocupada com o meio ambiente podem optar pela implementação de um Sistema de Gestão Ambiental (SGA).

A gestão ambiental consiste, segundo a ABNT NBR ISO 14.001:2015 (ABNT, 2015), em um conjunto de requisitos e política bem definida que possibilitam reduzir e controlar os impactos gerados por um empreendimento sobre o meio ambiente. Já para Alberton e Costa Jr. (2007), trata-se da adequação das práticas empresariais para que seus resultados sejam compatíveis com uma abordagem sustentável, influenciando na geração e descarte de resíduos sólidos da organização. Os autores também afirmam que uma vez implantado o SGA, o desempenho ambiental da empresa passa a influenciar diretamente na satisfação financeira, causando efeitos positivos, como a diminuição de desperdícios e a melhoria da imagem da empresa, podendo tal aspecto ser utilizado em campanhas de marketing. 0 SGA, por sua abrangência, poderá contemplar a redução da geração de resíduos, a responsabilidade social, a conscientização ambiental dos colaboradores, que pode reduzir o consumo de matérias-primas e reduzir a poluição. Além disso, a conformidade com a regulamentação ambiental traz vantagem competitiva para alcançar a sustentabilidade através do aprendizado, desenvolvimento contínuo e melhoria da eficiência, que pode incluir a eficiência administrativa e ambiental (Reis, 2002).

Pensando nas empresas de mecânica automotiva, a implementação de um SGA contribuirá fortemente no controle dos resíduos advindos de seus serviços. Instrumentos como a norma ABNT NBR ISO 14.001:2015 e a própria Política Nacional de Resíduos Sólidos, Lei no 12.305/2010 (Brasil, 2010), podem servir de apoio à consolidação deste sistema. Neste contexto, a Lei no $12.305 / 2010$ determina que estão sujeitas à elaboração de plano de gerenciamento de resíduos sólidos (PGRS) as empresas comerciais, industriais e de prestação de serviços que gerem resíduos perigosos e que por algum motivo não sejam equiparados aos domiciliares. As oficinas, por gerarem resíduos com tais características, estão sujeitas ao cumprimento desta obrigatoriedade.

Com relação à responsabilidade das empresas para com o meio ambiente, elas são responsáveis pelos resíduos gerados por suas atividades, de acordo com PNRS (Brasil, 2010). A norma ABNT NBR 10.004:2004 (ABNT, 2004) define os resíduos sólidos como sendo:

\begin{abstract}
Resíduos nos estados sólidos e semissólido, que resultam de atividades de origem industrial, doméstica, hospitalar, comercial, agrícola, de serviços e de varrição. Ficam incluídos nesta definição os lodos provenientes de sistemas de tratamento de água, aqueles gerados em equipamentos e instalações de controle de poluição, bem como determinados líquidos cujas particularidades tornem inviável o seu lançamento na rede pública de esgotos ou corpos de água, ou exijam para isso soluções técnica e economicamente inviáveis em face à melhor tecnologia disponível.
\end{abstract}

Esta mesma ABNT NBR 10.004:2004 (ABNT, 2004), classifica os resíduos sólidos quanto ao risco à saúde pública e ao meio ambiente (Tabela 1). Os resíduos sólidos são classificados em dois grupos - perigosos (Classe I) e não perigosos (Classe II), sendo ainda este último grupo subdividido em não inerte (Classe IIA) e inerte (Classe IIB).

Os resíduos gerados devem ficar armazenados separadamente, conforme suas classificações, em locais cobertos, abrigados das chuvas e outros eventos, garantindo a segurança e evitando as alterações de suas características e classificação até o transporte para os locais nos quais receberão tratamento ambientalmente adequado (ABNT NBR 10.004:2004). 0 armazenamento dos óleos e efluentes deve ocorrer em recipientes, como latões, galões, contêineres plásticos ou tanques, que devem estar cercados por diques de contenção, evitando problemas por vazamento ou rompimento dos recipientes e contato 
dos resíduos com o solo. Os recipientes para armazenagem dos resíduos devem estar identificados (ABNT NBR 12.235:2013).

Tabela 1. Classificação dos resíduos e potencial de risco ao meio ambiente.

\begin{tabular}{|c|c|c|}
\hline \multicolumn{2}{|c|}{ Classe/Classificação } & Riscos potenciais ao meio ambiente \\
\hline \multicolumn{2}{|c|}{ Classe I - Perigosos } & $\begin{array}{l}\text { Apresentam riscos à saúde pública e ao meio ambiente apresentando } \\
\text { uma ou mais das seguintes características: periculosidade, } \\
\text { inflamabilidade, corrosividade, reatividade, toxicidade e } \\
\text { patogenicidade. São exemplos as baterias, pilhas, óleo usado, resíduo de } \\
\text { tintas e pigmentos, resíduo de serviços de saúde, resíduo inflamável, } \\
\text { etc. }\end{array}$ \\
\hline \multirow[b]{2}{*}{ Classe II } & $\begin{array}{c}\text { Classe II A - não } \\
\text { inertes }\end{array}$ & $\begin{array}{l}\text { Não se enquadram nas classificações I e II B. Podem ter propriedades } \\
\text { como combustibilidade, biodegradabilidade e solubilidade em água. } \\
\text { São exemplos os lodos de estações de tratamento de água e esgoto, } \\
\text { papel, restos de alimentos. }\end{array}$ \\
\hline & $\begin{array}{c}\text { Classe II B - } \\
\text { inertes }\end{array}$ & $\begin{array}{l}\text { Quando amostrados de forma representativa e submetidos a um } \\
\text { contato dinâmico e estático com água destilada ou deionizada, à } \\
\text { temperatura ambiente, não tiverem nenhum de seus constituintes } \\
\text { solubilizados a concentrações superiores aos padrões de potabilidade } \\
\text { de água, excetuando-se aspecto, cor, turbidez, dureza e sabor. Como } \\
\text { exemplo destes materiais pode-se citar: tijolos, rochas, vidros, certos } \\
\text { plásticos e borrachas. }\end{array}$ \\
\hline
\end{tabular}

Fonte: ABNT (2004).

Com a mudança global frente às questões ambientais, as empresas se veem pressionadas a mudar sua forma de gestão. Ao se esforçarem para a adequação das demandas ambientais e por meio do incremento da sustentabilidade nos negócios, podem conquistar para além de prevenção de multas e penalidades legais, a fidelização dos clientes e atrair a preferência de outros. Além disto, podem agregar valor aos seus produtos e serviços, bem como se destacar diante de concorrentes. Desta forma o marketing ambiental se torna uma estratégia empresarial (Scheidt-Junior et al., 2015). No caso de empresas prestadores de serviços, esta valorização nem sempre é simples de ser percebida pelos consumidores. Segundo Bertolini et al. (2012) a relação dos consumidores com a variável ambiental é praticamente envolvida no produto e não no processo das empresas. Ainda conforme os autores, um sistema de exaustão instalado na empresa, os cuidados com a segregação e destinação de resíduos, por exemplo, dificilmente será percebido pelo consumidor. Estes, por sua vez, podem ser itens a serem fiscalizados pelos órgãos ambientais.

Independente da forma como as atitudes ambientais possam chegar aos consumidores, a simples mudança de postura costuma trazer resultados positivos para as empresas, que para Campos (2011) e Bertolini et al. (2012), tendem a destacar a melhoria da imagem institucional, a valorização da marca e a maior aceitabilidade dos produtos e serviços oferecidos por elas. Além disso, pontuam também a chamada diferenciação perante os concorrentes, o que impacta em ganho de clientes, assim como um natural vínculo das atividades destas com uma consequência positiva na mente dos consumidores. Essas razões influenciam diretamente na sobrevivência e rentabilidade, uma vez que o tema ambiental pode prover vantagem competitiva no mercado atual, gerando resultados econômico-financeiros positivos (Campos, 2011; Bertolini et al., 2012). 
Assim, surge a questão como a implantação de práticas de gestão e educação ambiental em oficina de reparação automotiva pesada pode propiciar melhora do desempenho organizacional em termos de processos e serviços? Objetivou-se com está pesquisa analisar a gestão de resíduos sólidos gerados nas atividades de uma oficina mecânica e identificar como práticas de gestão ambiental podem contribuir para a melhora do desempenho organizacional da oficina em termos de processos e serviços.

\section{Metodologia}

Para o presente estudo a coleta de dados e informações foi realizada em uma empresa de manutenção mecânica pesada (caminhões) de pequeno porte, localizada em Lajedo, no Vale do Taquari, Estado do Rio Grande do Sul. O desenvolvimento da pesquisa foi em duas etapas: (a) aplicação de um questionário estruturado com 12 perguntas, objetivas e discursivas, com todos os colaboradores, sendo três exclusivamente direcionadas para os gestores da empresa; e (b) visita técnica com auxílio de um checklist para registro e tabulação das observações. Inicialmente, realizou-se um primeiro contato com o proprietário para explicar as intenções da pesquisa e debater seus principais problemas enfrentados, relacionados às questões ambientais e posteriormente as visitas para a coleta de dados. Participaram da pesquisa o quadro funcional da empresa, composto por oito pessoas, das quais duas são os gestores (chefe de oficina e gerente administrativo/financeiro) e seis funcionários (dois mecânicos e quatro auxiliares).

A etapa de observação in loco para obtenção dos dados e verificação das condições de coleta e destinação dos resíduos foi realizada mensalmente, totalizando cinco visitas, de setembro de 2019 a janeiro de 2020. As observações das visitas foram registradas em um checklist específico previamente elaborado pelos autores. Em paralelo às visitas, foi aplicado um questionário para todos os colaboradores da empresa, gestores e funcionários, a fim de identificar questões relacionadas à compreensão das práticas ambientais inerentes a função que desenvolvem. 0 questionário foi do tipo estruturado, com questões objetivas e discursivas.

Após a análise das observações e dos dados coletados, seja para atender a legislação em vigor quanto para trazer melhorias a dinâmica do empreendimento, foram propostas melhorias ao empreendedor para que ele pudesse avaliar e providenciar a implementação das mesmas. Posteriormente, com base nas observações durante as visitas, evolução das constatações do checklist, implantação das possibilidades de melhorias apontadas e respostas obtidas com a aplicação do questionário, foi avaliado se a prática de gestão ambiental contribui na melhora do desempenho organizacional da oficina em termos de processos e serviço.

\section{Resultados e discussão}

\section{A empresa e diagnóstico dos resíduos sólidos}

A empresa estudada, enquadrada como microempresa, está localizada Município de Lajeado, estado do Rio Grande do Sul. Fundada em 2016. Seus serviços estão concentrados na troca de óleo lubrificante, troca e limpeza de peças, consertos em injeção eletrônica, suspensão, freios e regulagem de motor, perfazendo em torno de 50 atendimentos mensais. Entre os principais resíduos produzidos por essas atividades estão os óleos lubrificantes usados, combustível e fluídos químicos em geral, chapas metálicas, peças defeituosas, lonas de freio, embalagens de óleo, lixas e estopas usadas, filtros de combustível e óleo, papel, papelão e plásticos. A Tabela 2 resume os tipos de resíduos sólidos encontrados na mecânica durante a observação in loco, oriundos dos serviços prestados, suas características quanto à classificação do resíduo (de acordo com a ABNT 
NBR 10.004:2004), sua forma de acondicionamento e armazenamento temporário e sua destinação final.

Seus serviços estão concentrados na troca de óleo lubrificante, troca e limpeza de peças, consertos em injeção eletrônica, suspensão, freios e regulagem de motor, perfazendo em torno de 50 atendimentos mensais Entre os principais resíduos produzidos por essas atividades estão os óleos lubrificantes usados, combustível, massas e fluídos químicos em geral, chapas metálicas, peças defeituosas, lonas de freio, embalagens de óleo, lixas e estopas usadas, filtros de combustível e óleo, papel, papelão e plásticos.

Tabela 2. Tipos e destinação dos resíduos sólidos gerados pela mecânica geral de veículos pesados.

\begin{tabular}{|c|c|c|c|c|}
\hline Resíduo & Classe & Acondicionamento & $\begin{array}{c}\text { Local de } \\
\text { armazenamento } \\
\text { temporário }\end{array}$ & Destinação final \\
\hline Óleo usado & I & $\begin{array}{c}\text { Tambor plástico } \\
1.000 \mathrm{~L}\end{array}$ & $\begin{array}{c}\text { Área de lavagem de } \\
\text { peças da oficina }\end{array}$ & Refino \\
\hline Sucata Mista & II-B & $\begin{array}{l}\text { Tonel } 200 \mathrm{~L} \text { ou a } \\
\text { granel }\end{array}$ & \multirow{3}{*}{ Depósito de resíduos } & Reciclagem \\
\hline $\begin{array}{l}\text { Sucata } \\
\text { alumínio }\end{array}$ & II-B & $\begin{array}{l}\text { Tonel } 200 \mathrm{~L} \mathrm{ou} \mathrm{a} \\
\text { granel }\end{array}$ & & Reciclagem \\
\hline $\begin{array}{l}\text { Contaminados } \\
\text { diversos* }\end{array}$ & I & Tonel $200 \mathrm{~L}$ & & $\begin{array}{c}\text { Blendagem e/ou } \\
\text { aterro }\end{array}$ \\
\hline $\begin{array}{l}\text { Efluente de } \\
\text { limpeza da caixa } \\
\text { separadora }\end{array}$ & I & Separador água e óleo & Separador água e óleo & $\begin{array}{l}\text { Tratamento do } \\
\text { efluente }\end{array}$ \\
\hline
\end{tabular}

*Contemplam papel, papelão, plásticos, filtros de óleo e combustível usados, panos, estopas, lonas de freio, embalagens de óleo. Fonte: Elaborado pelos autores.

Realizar o acompanhamento da produção e destinação dos resíduos dentro de uma empresa é de extrema importância. Fazer esse registro permite o acompanhamento e a evolução da empresa a partir da implementação das práticas de gestão ambiental e tomar decisões que podem impactar positivamente na empresa, principalmente no financeiro. Devemos destacar que a mecânica auditada neste estudo mantém registrado o histórico de geração e destino dos seus resíduos desde a sua fundação, conforme apresentado na Figura 1.

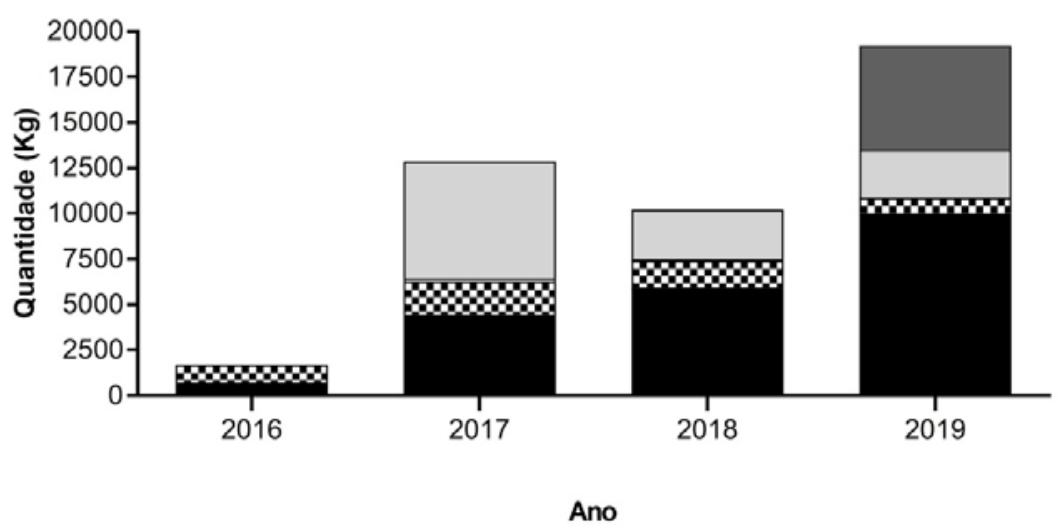

- Oleo usado $\infty$ Sucata mista $\square$ Sucata de aluminio $\square$ Contaminados diversos $\square$ Residuo limpeza caixa separadora

Figura 1. Levantamento do quantitativo de resíduos gerados e destinados para descarte. 
O estabelecimento de reparação automotiva pesada produziu, durante os quatro anos de funcionamento, um total de $43.992,5 \mathrm{~kg}$ de resíduos, sendo $21.080 \mathrm{~kg}$ de óleo usado; $5.119 \mathrm{~kg}$ de sucata mista; $250 \mathrm{~kg}$ de sucata de alumínio; 11.843,5 kg de contaminados diversos; e $5.700 \mathrm{~kg}$ resíduo/efluente da limpeza da caixa separadora. Considerando o tipo de resíduo, a produção da classe I foi 7,2 vezes maior que da classe II, totalizando $38.623,5 \mathrm{~kg}$ e $5.369 \mathrm{~kg}$, respectivamente. Destaque-se um aumento significativo de geração de resíduos entre os anos 2016 e 2017 devido ao início recente das atividades da oficina, fazendo com que o empreendedor optasse por acumular os resíduos do ano anterior para evitar despesas extras durante o período de consolidação da empresa.

A partir da Figura 1 é possível identificar que predomina a geração de resíduos oleosos (total de $21.080 \mathrm{~kg}$ ), sendo eles o óleo usado, oriundo das trocas de óleo dos caminhões, e os resíduos gerais contaminados com óleo e/ou graxa, que são gerados em grande parte dos serviços de manutenção ou reparação prestados. Esse resultado já era esperado devido ao tipo de serviço prestado pela empresa. A predominância dessa tipologia de resíduo também foi evidenciada por Lopes e Kemerich (2007), que avaliaram os resíduos gerados em uma oficina mecânica de empresa de transporte coletivo, durante o período de um ano. Ademais, diferentemente dos resultados deste estudo, houve predominância da geração de resíduos metálicos - sucatas (basicamente molas, peças e ferro fundido).

No decorrer dos quatro anos de atividades, houve aumento progressivo da geração de resíduos Classe I (óleo, contaminados diversos, resíduo/efluente da limpeza da caixa separadora) em 10,8 vezes entre os anos de 2016-2019, com destaque para o último ano com 18.370 kg e redução gradual na geração de resíduos Classe II (sucatas metálicas). A redução da maior produção do resíduo Classe II (2017) para o menor (2019) foi de 2,4 vezes. Este comportamento, conforme o empreendedor, pode ser associado ao aumento de serviços de manutenção preventiva, que acarreta na redução da necessidade de troca de componentes danificados.

\section{Entendimento e compreensão dos gestores e colaboradores em relação às boas práticas ambientais}

Para uma implementação efetiva das práticas ambientais em um estabelecimento comercial é necessário conhecimento e entendimento teórico conceitual sobre a área ambiental e práticas diretamente relacionadas às suas atividades por parte de todos os colaboradores, inclusive dos gestores. De acordo com a Política Nacional de Educação Ambiental (PNEA) a Educação Ambiental deve ser abordada em todos os níveis de ensino, desde a educação formal até a não formal (Gonzaga et al., 2015). Quando os colaboradores são munidos desse conhecimento, "[...] mostram-se mais receptivos às mudanças e proativos na medida em que o processo de treinamento seja coerentemente conduzido e avaliado pela organização" (Oliveira e Pinheiro, 2010, p. 59). Além disso, percebe-se uma ampliação da "[...] sua visão sobre o processo de mudança, transformando o conhecimento em vantagem competitiva" (Oliveira e Pinheiro, 2010, p. 59).

No empreendimento estudado, a partir do questionário aplicado com gestores e colaboradores $(n=8)$, foi possível constatar que a compreensão e entendimento frente a questões ambientais inerentes às atividades que desempenham foi satisfatório (Tabela 3). De modo geral, o percentual médio de acerto das questões aplicadas foi de $89,6 \%$, demonstrando que o quadro funcional da empresa apresenta considerável conhecimento a respeito de conceitos básicos da área ambiental e práticas diretamente relacionadas às suas atividades. Mesmo considerando o resultado satisfatório, vale salientar que as dúvidas recorrentes entre os colaboradores são conceituais, sendo necessário saná-las através de treinamento. Cabe destaque que o questionário buscou utilizar termos 
comumente utilizados na prática, visando à aproximação à linguagem e à compreensão dos colaboradores.

Esse entendimento é significativo, uma vez que, uma boa educação ambiental dos colaboradores tende a representar maior engajamento destes, garantindo a gestão correta e sustentável e gerando mudanças positivas no cotidiano da empresa no que se refere as questões ambientais (Oliveira, 2015). Ao encontro disso, deve-se considerar também o ganho comunitário desta conscientização no contexto social ao qual o colaborador está inserido, que também acaba gerando benefícios para a sociedade quando este aplica ou dissemina seus conhecimentos.

Tabela 3. Questionamento apresentados aos gestores e aos colaboradores em relação à prática ambiental

\begin{tabular}{|l|r|}
\hline Questão & \% acerto \\
\hline 1 - O que é lixo? & $75,0 \%$ \\
\hline 2 - O que significa cada R da Política dos 3 R's? & $100,0 \%$ \\
\hline 3 - Por que devo separar o lixo? & $100,0 \%$ \\
\hline 4 - O que são resíduos considerados contaminados? & $87,5 \%$ \\
\hline 5 - O que são resíduos considerados não contaminados? & $75,0 \%$ \\
\hline 6 - A respeito dos efluentes líquidos industriais, assinale a alternativa correta. & $100,0 \%$ \\
\hline Percentual médio de acerto & $\mathbf{8 9 , 6 \%}$ \\
\hline
\end{tabular}

Além das questões acima, também foram aplicados três questionamentos discursivos, sendo o primeiro deles: "7 - Já participou de algum treinamento ou palestra que tratava de questões ambientais como separação do lixo, por exemplo? 0 que aprendeu?". Percebeu-se que 62,5\% dos entrevistados não participaram de nenhum tipo de treinamento e $37,5 \%$ respondeu já ter participado. Devemos considerar que para ter um bom funcionamento do SGA na empresa é necessário treinamento, que será a ferramenta fomentadora, nos funcionários, do aprendizado e da adaptação aos novos conhecimentos e habilidades, aumentando a competitividade da organização como um todo (Oliveira e Pinheiro, 2010). Os respondentes destacaram como aprendizado "dar destino correto ao resíduo é ser a prova mais humana de mantermos limpos o nosso planeta", bem como o fato do "tema ser essencial para o desenvolvimento de qualquer sociedade porque saber separar o lixo corretamente é o primeiro passo para a destinação, disposição e tratamento".

Ao avaliar as respostas da sétima questão, chama atenção o fato de que um elevado percentual dos participantes informou não ter participado de nenhum treinamento anteriormente, fato que, de certo modo, se contrapõe ao bom índice de acertos das questões apresentadas na Tabela 3. Este contraponto entre os índices leva a crer que os gestores do empreendimento, por sua preocupação, postura favorável com meio ambiente e exigência de que os cuidados ambientais façam parte da rotina de trabalho de cada um dos seus colaboradores, sejam determinantes para compreensão e entendimento das questões ambientais inerentes ao seu trabalho. Também devemos considerar que, na atualidade, está em alta o tema "preservação ambiental" que influencia diretamente na vida da sociedade. Outra hipótese a considerar seria a educação em âmbito escolar, que pode ter sido ignorada pelos respondentes.

Para os 37,5\% que já participaram de alguma palestra ou treinamento, o ponto positivo identificado em suas respostas foi a conscientização da importância e ganhos para a sociedade que uma separação e destinação correta dos resíduos pode propiciar. Para 
Marshall-Junior (2001, p. 104), “através de suas atitudes, o funcionário revelará a cultura que adquiriu, sentindo-se responsável pelo meio ambiente, algo que pode traduzir uma peça da engrenagem maior: responsabilidade social". 0 autor ainda destaca que o funcionário inicia um envolvimento sem volta, quando é integrado no processo de implementação da gestão ambiental da empresa, por perceber que o contexto ambiental diz respeito a um fenômeno global.

A segunda questão aberta foi "8 - Como você pode contribuir para melhorar os cuidados ambientais da empresa?", cujas respostas pontuaram a "separação correta dos resíduos para destino adequado e evitar contaminação do solo, não desperdiçar água, não utilizar copos descartáveis e redução do uso de produtos desengraxantes". A questão foi respondida pelos participantes na sua totalidade. É observado nos comentários um perfil voltado para a economia, tanto evitando o desperdício como o consumo exagerado de insumos, estando vinculado com a redução de custos por parte da empresa. Além da responsabilidade social gerada pelo envolvimento e aprendizado adquiridos pelos funcionários sobre as questões ambientais, os mesmos se tornam parte integrante do bom desenvolvimento econômico da empresa e responsáveis pela saúde do meio ambiente (Marshall-Junior, 2001).

A terceira e última questão aberta solicitava "9 - Dê 3 exemplos de cuidados com o meio ambiente, que podem ser melhorados na empresa". Dos participantes, 87,5\% responderam à questão, trazendo como exemplos "mentalidade de consumo, economia colaborativa e compartilhada, cuidados com produtos fortes, seguir as regras da empresa, economia de energia, descarte dos resíduos em lugares adequados, não descartar óleo lubrificantes da rede de esgoto no piso ou local sem piso, deixar tudo organizado, jogar o lixo no seu devido lugar, respeitar o meio ambiente, produzir menos lixo em geral $e$ contaminados em específico, usar produtos de limpeza biodegradáveis e sinalização mais adequada para cada tipo de lixo". São vários os benefícios decorrentes da gestão ambiental, geração de resíduos reduzidos; diminuição do consumo de água e energia e consequentemente redução de custos; aumento da ecoeficiência; melhoria de processos; eleva o faturamento; funcionários passam a ser mais autônomos; retenção e satisfação aumentada de clientes e a melhoria da imagem institucional (Marshall-Junior, 2001).

A partir das respostas das Questões 8 e 9, é possível evidenciar que o satisfatório conhecimento a respeito de alguns conceitos da área ambiental e práticas diretamente relacionadas às atividades da oficina, observado no índice de acertos $(89,6 \%)$ da Tabela 3 , se reflete nas respostas dos respondentes. Os exemplos de como cada um poderia melhorar os cuidados ambientais da empresa, assim como as sugestões do que poderia ser melhorado na sua visão, demonstram que os mesmos estão atentos e atuantes no processo de gestão ambiental da empresa.

Visita técnica para levantamento das não conformidades e proposições de adequações visando ao atendimento à legislação ambiental

No decorrer da realização das cinco visitas técnicas, foi possível identificar diversos pontos positivos e negativos em relação às medidas que a empresa vem adotando, em conformidade com as normas ABNT NBR 10.004:2004 (ABNT, 2004), ABNT NBR 12.235:2013 (ABNT, 2013) e Resolução CONAMA no 275/2001 (Brasil, 2001), para reduzir a geração ou os impactos ambientais decorrentes dos resíduos sólidos e melhora no desempenho das suas atividades. Destaca-se: o desempenho das atividades sob área provida de piso impermeável, sem rachaduras (Figura 2-A); o aproveitamento de iluminação natural em grande parte da área da empresa (Figura 2-B); e a presença de sistema de tratamento de efluentes, que é monitorado periodicamente. 

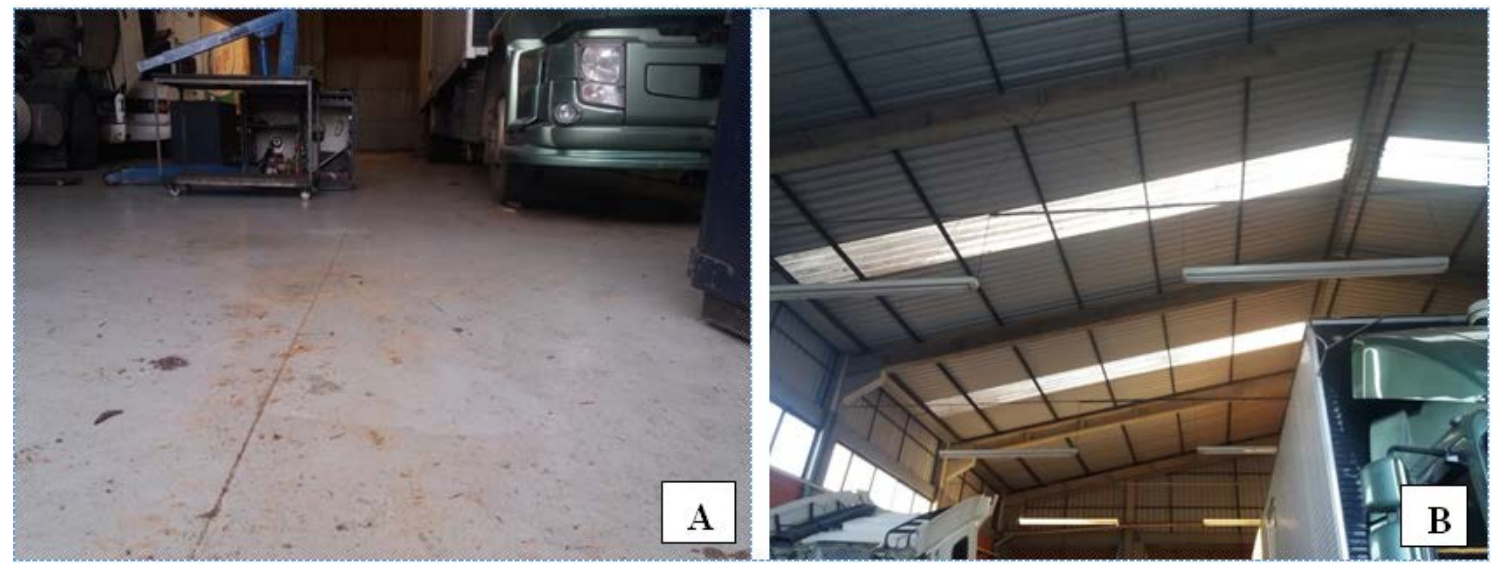

Figura 2. Conformidades identificadas no empreendimento (26 fev. 2020).

Com relação aos resíduos sólidos gerados, observou-se que os mesmos são armazenados em área externa da empresa, coberta, sem piso impermeável, exceto o óleo usado, que é armazenado em tambor de $1.000 \mathrm{~L}$ próxima à área de lavagem de peças, sob piso impermeável. No entanto, não se observa identificação quanto a tipologia nos recipientes de descarte dos resíduos, os mesmos eram dispostos separadamente, conforme tipologia e potencial de contaminação nos diversos tonéis da central de armazenamento.

Como uma não conformidade, registrou-se, na primeira visita técnica, derramamento de fluído de freio em local desprovido de piso, que foi imediatamente absorvido com serragem pelo empreendedor. Em visitas técnicas posteriores, não foi verificada reincidência semelhante. Na central de armazenamento de resíduos não foi observada identificação dos recipientes, indicando a tipologia a ser descartada em cada um, além do local ser desprovido de piso impermeável; os recipientes encontram-se dispostos somente sobre brita, o que pode permitir a contaminação do solo em caso de algum vazamento de óleo de peça ou material não drenado suficientemente.

$\mathrm{Na}$ área de lavagem de peças, observou-se que o recipiente que armazena o óleo usado não está provido de bacia de contenção, situação amenizada pelo fato de se encontrar sobre piso impermeável, interligado com o sistema de tratamento de efluentes da empresa. Tal interligação impede que, em caso de vazamento, o óleo contamine o solo ou escoe para a drenagem pluvial, atuando indiretamente como mecanismo de contenção.

Frente aos pontos negativos levantados foram propostas algumas melhorias ao empreendedor, apresentadas na Tabela 4.

Após as sugestões apresentadas para a empresa e dentre as não conformidades apontadas, foi providenciado a impermeabilização do piso e implantação de mureta de contenção na central de armazenamento de resíduos, cuja execução pode ser visualizada na Figura 3. 
Tabela 4. Propostas de adequações das não conformidades levantadas na visita técnica.

\begin{tabular}{|c|c|c|c|c|}
\hline Ponto negativo & Melhoria proposta & Local (setor) & $\begin{array}{c}\text { Norma } \\
\text { pertinente }\end{array}$ & $\begin{array}{c}\text { Benefícios da } \\
\text { implantação }\end{array}$ \\
\hline $\begin{array}{l}\text { Falta } \\
\text { identificação dos } \\
\text { recipientes } \\
\text { acondicionadores } \\
\text { de resíduos }\end{array}$ & $\begin{array}{l}\text { - Providenciar a } \\
\text { identificação } \\
\text { recipientes conforme } \\
\text { tipologia de resíduo a ser } \\
\text { disposta em cada um. } \\
\text { - Implantar um sistema de } \\
\text { cores, placas ou mesmo } \\
\text { lixeiras diferenciadas para } \\
\text { cada tipo de resíduo gerado }\end{array}$ & $\begin{array}{l}\text { Central de } \\
\text { armazename } \\
\text { nto de } \\
\text { resíduos. }\end{array}$ & $\begin{array}{l}\text { Resolução } \\
\text { CONAMA no } \\
275 / 2001\end{array}$ & $\begin{array}{l}\text { Facilitar a } \\
\text { segregação do } \\
\text { material na hora } \\
\text { do descarte pelo } \\
\text { usuário/gerador. }\end{array}$ \\
\hline $\begin{array}{lr}\text { Inexistência } & \text { de } \\
\text { piso } & \\
\text { impermeável } & \text { e } \\
\text { contenção } & \text { de } \\
\text { vazamentos } & \end{array}$ & $\begin{array}{l}\text { - Providenciar } \\
\text { impermeabilização do piso } \\
\text { e implantação de mureta de } \\
\text { contenção } \\
\text { aproximadamente } 0,1 \mathrm{~m}\end{array}$ & $\begin{array}{l}\text { Central de } \\
\text { armazename } \\
\text { nto de } \\
\text { resíduos. }\end{array}$ & $\begin{array}{l}\text { ABNT } \quad \text { NBR } \\
12.235: 2013\end{array}$ & $\begin{array}{l}\text { Conter eventual } \\
\text { vazamento de } \\
\text { óleo dos filtros, } \\
\text { embalagens } \\
\text { vazias ou outro } \\
\text { item sem } \\
\text { drenagem } \\
\text { eficiente. }\end{array}$ \\
\hline
\end{tabular}
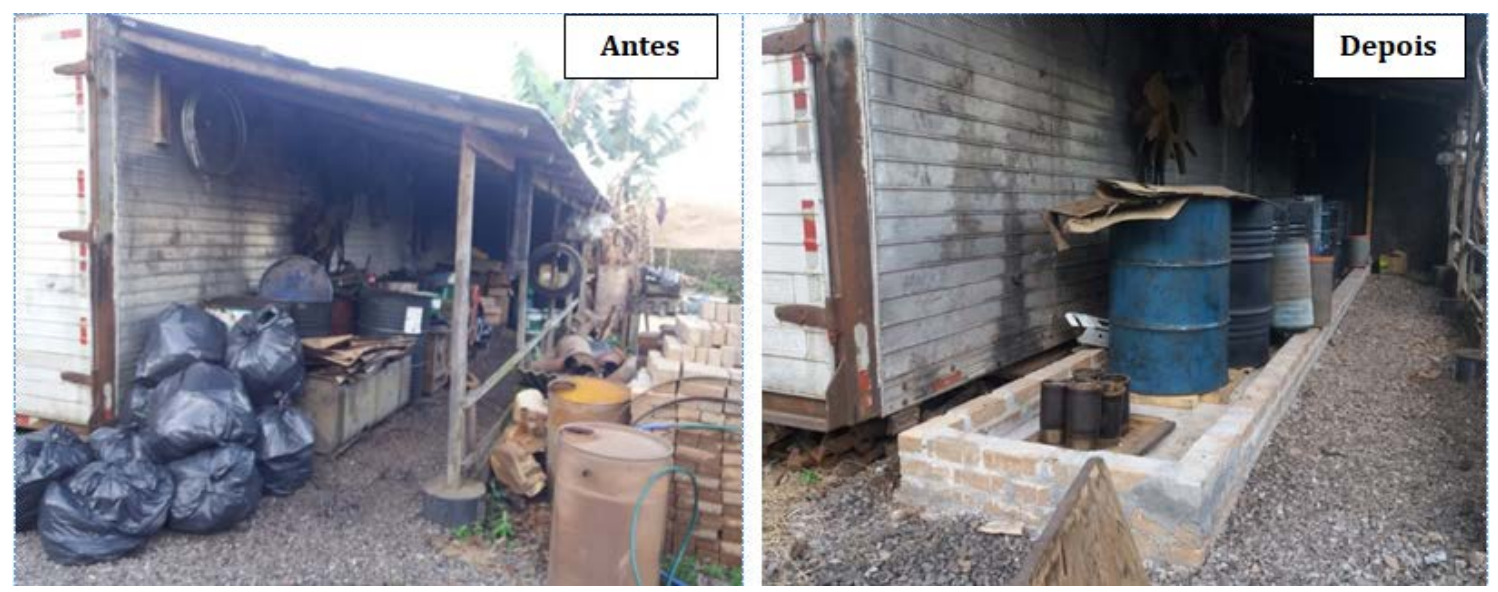

Figura 3. Execução de melhoria proposta durante o estudo - antes e depois (18 set. 2019).

\section{Gestão ambiental na melhora do desempenho organizacional da empresa}

Com as questões aplicadas apenas aos gestores, buscou-se identificar como é percebido o posicionamento da empresa no ambiente interno e externo. Os questionamentos feitos foram: "10 - São observados benefícios decorrentes dos cuidados ambientais que empresa adota?"; "11 - Qual o retorno percebido por parte dos clientes pelos cuidados ambientais que a empresa adota?" e "12 - Quais as dificuldades para adoção e implementação de cuidados ambientais atualmente?"

Em relação aos benefícios observados, um dos gestores aponta que perante os clientes não é percebido nenhum benefício atualmente, no entanto, perante a responsabilidade da empresa, são observadas vantagens visto que quanto mais corretos forem os cuidados, mais estarão contribuindo com o meio ambiente. 0 segundo gestor respondente também percebe benefícios nas atividades da oficina, apesar dos gastos com destinação de resíduos contaminados, salientando que é necessário adotar uma política de separação adequada, visto que geram diversos tipos de resíduos. Para Marshall-Junior (2001), pensando de forma reacionária, pode parecer, um investimento sem retorno, no 
entanto, a permanência da empresa no mercado depende diretamente da postura em relação ao meio ambiente.

A percepção dos gestores está alinhada, em parte, a de algumas bibliografias. 0 estudo de Mangueira et al. (2015), realizado com 267 proprietários de oficinas de linha leve, conclui que a gestão ambiental influenciou positivamente o desempenho organizacional das suas empresas. Destacam ainda, que as práticas empregadas nessas oficinas se concentram na busca da conformidade ambiental, apesar de ainda ser incipiente a maturidade do setor em termos de práticas de gestão ambiental.

Ao abordar o retorno percebido por parte da clientela, ambos destacam não observar retorno dos seus clientes em relação à política ambiental da empresa, sendo nula esse tipo de conscientização em seu público. Um deles pontua que "o cliente pensa em caminhão, não se preocupando com a empresa ou questões relativas a como separar o lixo corretamente". Em um estudo realizado por Donato et al. (2016), que entrevistou 68 clientes e 68 potenciais clientes de uma oficina de reparação do estado do Paraná, trouxe dados que merecem atenção no setor de serviços, sendo possível compreender a percepção dos gestores da presente pesquisa. No estudo, embora a valorização de ações ambientais em ambos os grupos tenha sido alta, os entrevistados responderam que não têm o hábito de efetivamente buscar por alternativas de produtos e serviços ambientalmente corretas.

Quando ambos os públicos foram questionados sobre os critérios de escolha de determinada oficina de reparação, somente 5\% apontou a Responsabilidade Ambiental como fator determinante. Foi a última das características consideradas para a escolha; os respondentes priorizam como características a qualidade dos serviços, o atendimento, e o preço (Donato et al., 2016). Resultados que, segundo Bertolini et al. (2012), podem ser justificados devido aos clientes valorizarem produtos ecológicos e não processos adequados quanto ao meio ambiente.

No decorrer do estudo, se observou que a empresa não tem por hábito promover a divulgação da empresa e serviços, ação que poderia ser explorada mediante vinculação das ações e cuidados ambientais atrelados às atividades que desempenha. Scheidt-Junior et al. (2015) apontam que um marketing ambiental pode ser uma boa estratégia empresarial para atrair a fidelidade de clientes e preferência de outros, agregar valor aos serviços, além de se destacar diante dos concorrentes. Além disso, o marketing feito para dentro da empresa, o endomarketing ou marketing interno, também pode ser adotado com estratégia, em razão do "público interno transmitir a imagem da empresa e vender os produtos e serviços ao cliente externo" (Brum, 2010; Costa, 2014).

Por fim, quando solicitados a indicar as dificuldades para adoção e implementação de cuidados ambientais, os gestores apresentaram pontos de vista distintos. Um deles indicou a conscientização das pessoas para dar destino correto aos resíduos e o outro os fatores como custo, a burocracia e uma falta de suporte por parte do poder municipal, para saber como proceder corretamente com a questão.

A partir das respostas, é perceptível que no âmbito da empresa a questão da conscientização encontra-se em condição satisfatória conforme já apresentado anteriormente. Questões como custo merecem muita atenção pois alguns investimentos podem não proporcionar o resultado desejado. Bertolini et al. (2012) apontam que cuidados com o meio ambiente demandam recursos financeiros para que sejam viabilizados, devendo haver uma análise de viabilidade prévia a fim de verificar o retorno apropriado para a empresa.

\section{Conclusões}

A partir dos resultados apresentados, ficou evidenciado que a empresa adota processos adequados de gestão ambiental através do gerenciamento correto de seus 
resíduos, seguindo a legislação vigente, apesar do apontamento de algumas não conformidades que podem ser melhoradas. Além disso, o quadro de colaboradores possui satisfatória compreensão e entendimento frente às questões ambientais inerentes às atividades que desempenham, apesar de não terem passado por treinamentos. Ademais, os cuidados e práticas ambientais que a empresa adota são vistos como positivos, propiciando um melhor desempenho organizacional, apesar desta percepção ocorrer somente no âmbito interno.

\section{Conflito de interesses}

Os autores declaram não haver conflito de interesses.

\section{Referências}

ABNT - Associação Brasileira de Normas Técnicas. ABNT NBR 10.004: Resíduos Sólidos Classificação. Rio de Janeiro: ABNT, 2004.

ABNT - Associação Brasileira de Normas Técnicas. ABNT NBR ISO 12.235: Armazenamento de resíduos sólidos perigosos. Rio de Janeiro: ABNT, 2013.

ABNT - Associação Brasileira de Normas Técnicas. ABNT NBR ISO 14.001: Sistemas da gestão ambiental - Requisitos com orientações para uso. Rio de Janeiro: ABNT, 2015.

Alberton, A.; Costa Jr., N. C. A. Meio ambiente e desempenho econômico-financeiro: benefícios dos sistemas de gestão ambiental (SGAs) e o impacto da ISO 14001 nas empresas brasileiras. RAC-Eletrônica, v. 1, n. 2, p. 153-171, 2007.

Belfi, T. G.; Lima, M. C.; Milagres, P. F.; Assis, N. F. S.; Castilho, R. A. A. Projeto de regularização e adequação ambiental de oficinas mecânicas. Anais do V Congresso Brasileiro de Gestão Ambiental, Minas Gerais, 2014. Disponível em: <http://www.ibeas.org.br/congresso/Trabalhos2014/V-009.pdf>. Acesso em: 02 mar. 2020.

Bertolini, G. R. F.; Rojo, C. A.; Lezana, Á. G. R. Modelo de análise de investimentos para fabricação de produtos ecologicamente corretos. Gestão de Produção, v. 19, n. 3, p. 575-588, 2012. https://doi.org/10.1590/S0104-530X2012000300010

Brasil. Resolução CONAMA no 275, de 25 de abril de 2001. Estabelece o código de cores para os diferentes tipos de resíduos, a ser adotado na identificação de coletores e transportadores, bem como nas campanhas informativas para a coleta seletiva. Disponível em: <http://www.mma.gov.br/port/conama/legiabre.cfm?codlegi=273>. Acesso em: 02 mar. 2020.

Brasil. Lei no 12.305, de 2 de agosto de 2010. Institui a Política Nacional de Resíduos Sólidos; altera a Lei no 9.605, de 12 de fevereiro de 1998; e dá outras providências. Disponível em: <http://www.planalto.gov.br/ccivil_03/_ato2007-2010/2010/lei/l12305. htm>. Acesso em: 05 fev. 2020.

Brum, A. D. M. Endomarketing de A a Z: como alinhar o pensamento de pessoas à estratégia da empresa. São Paulo: Integrare, 2010.

Campos, I. F. Estratégia ambiental como vantagem competitiva: caso Ecomercado Palhano. Anais do VIII Simpósio de Excelência em Gestão e Tecnologia, Resende/RJ, 2011. Disponível em: <https://www.aedb.br/seget/arquivos/artigos11/2514440.pdf>. Acesso em: 06 fev. 2020. 
Costa, D. Endomarketing inteligente: a empresa pensada de dentro para fora. 2. ed. rev. e ampl. Porto Alegre: Dublinense, 2014.

Donato, E.; Vieira, V. B. H. A.; Johann, J. A.; Bertolini, G. R. F. A responsabilidade ambiental como vantagem competitiva em uma oficina de reparação de veículos. Revista Organizações em Contexto, v. 12, n. 24, p. 131-163, 2016. https://doi.org/10.15603/ 1982-8756/roc.v12n24p131-163

Gonzaga, E. A. R.; Ribeiro, L. F.; Araújo, E. H. Análise da percepção ambiental como instrumento para o planejamento de ações de educação ambiental para funcionários terceirizados na Universidade Federal de Uberlândia. Revista de Educação Popular, v. 14, n. 1, p. 121-134, 2015. https://doi.org/10.14393/REP-v14n12015-art10

Mangueira, F. O.; Figueiredo, A. L. C.; Gabriel, M. L. S. Análise dos efeitos da gestão ambiental no desempenho organizacional de oficinas de reparação automotiva no Município de São Paulo. Exacta, v. 13, n. 2, p. 263-273, 2015. https://doi.org/10.5585/ exactaep.v13n2.5746

Marshall-Junior, I. Certificação ambiental em empresas industriais: o caso Bayer e os reflexos na conscientização de seus funcionários e famílias. Revista de Administração Pública, v. 35, n. 3, p. 77-106, 2001.

Oliveira, O. J.; Pinheiro, C. S. Implantação de sistemas de gestão ambiental ISO 14001: uma contribuição da área de gestão de pessoas. Gestão \& Produção, v. 17, n. 1, p. 51-61, 2010. https://doi.org/10.1590/S0104-530X2010000100005

Oliveira, P. H.; João, H. F. C. E.; Mondlane, N. A. Contexto competitivo, monitoramento ambiental e tomada de decisão estratégica: o caso dos micro e pequenos varejos da região do Barro Preto em Belo Horizonte. Ciência da Informação, v. 37, n. 2, p. 110-121, 2008. https://doi.org/10.1590/S0100-19652008000200009

Oliveira, U. A educação ambiental como instrumento de gestão em empresas privadas. 2015. Disponível em: <https://administradores.com.br/artigos/a-educacaoambiental-como-instrumento-de-gestao-em-empresas-privadas $>$. Acesso em: 05 mar. 2020.

Reis, H. L. Os impactos de um sistema de gestão ambiental no desempenho financeiro das empresas: um estudo de caso. Anais do XXVI ENANPAD, Salvador, 2002. Disponível em: <http://www.anpad.org.br/admin/pdf/enanpad2002-fin-1858.pdf>. Acesso em: 05 mar. 2020.

Scheidt-Junior, A. S.; Picinin, R. B.; Medeiros, H. S. Gestão ambiental empresarial: resíduos sólidos problema ou solução? Anais do XI Congresso Nacional de Excelência em Gestão, Rio de Janeiro, FIRJAN-RJ, 2015. Disponível em: <https://www.inovarse.org/ sites/default/files/T_15_304_0.pdf>. Acesso em: 05 mar. 2020.

Silveira, E. S. B.; Pereira, M. F.; Costa, A. M.; Moritz, G. O.; Dalmau, M. Comportamento estratégico à luz da gestão ambiental. Revista de Administração FACES Journal, v. 9, n. 2, p. 119-133, 2010.

Informação da Licença: Este é um artigo Open Access distribuído sob os termos da Licença Creative Commons Attribution, que permite uso irrestrito, distribuição e reprodução em qualquer meio, desde que a obra original seja devidamente citada. 